\title{
Predictors of social support, physical health and mental health among food insecure internally displaced persons in Turkana, Kenya
}

Catherine Gichunge ${ }^{1 *}$, Daniel Mutiso ${ }^{2}$ and Jenny Brynjarsdottir ${ }^{3,4}$

\begin{abstract}
Background: Food insecurity and the mental and physical health of internally displaced persons (IDPs) is a public health concern. The aim of this study was to determine the predictors of social support, physical and mental health among food insecure IDPs in Nakwamekwei IDP camp in Turkana, Kenya.

Methods: A cross sectional study was conducted among 159 household heads living in the camp. Analysis was conducted using statistical summaries, logistic regression and linear regression.

Results: Ninety four percent (94\%) of the households were severely food insecure and the rest of the households had moderate food insecurity. Majority of the household heads (77\%) had symptoms of depression and those with five or more children were 3 times $(95 \% \mathrm{Cl}, 1.31-9.24 ; p=0.015)$ more likely to be have symptoms of depression, while those who were married were less likely to have the same $(95 \% \mathrm{Cl}, 0.14-0.92 ; p=0.038)$. Seventy six percent (76\%) of the household heads had anxiety symptoms; none of the predictor variables were significantly associated with anxiety symptoms in the adjusted analysis. Those who had spent many years in the camp, were older, and had more children had significantly poorer physical health $(p=0.042, p=0.001$, and $p=0.047$, respectively). Those who were married and those who had experienced violence in the current camp had significantly higher social support ( $p=0.001$ and $p=0.006$, respectively).

Conclusions: Participants have been living in camp for the last 10 years hence the need to improve their living conditions, address their physical and mental health as well as food insecurity. This can be done by providing the participants with safe drinking water, constructing pit latrines to prevent communicable disease and adhere to the Sphere recommendations for sanitation and hygiene as well as training them in income generating activities to mitigate the high unemployment and food insecurity rates. The IDPs should be integrated into the local community to bring an end to their protracted displacement.
\end{abstract}

Keywords: Internally displaced persons, Food insecurity, Mental health, Social support, Physical health, Turkana, Kenya

\footnotetext{
* Correspondence: cngichunge@gmail.com; cngichunge@chuka.ac.ke

${ }^{1}$ School of Nursing and Public Health, Chuka University, Chuka, Kenya

Full list of author information is available at the end of the article
}

(c) The Author(s). 2020 Open Access This article is licensed under a Creative Commons Attribution 4.0 International License, which permits use, sharing, adaptation, distribution and reproduction in any medium or format, as long as you give appropriate credit to the original author(s) and the source, provide a link to the Creative Commons licence, and indicate if changes were made. The images or other third party material in this article are included in the article's Creative Commons. licence, unless indicated otherwise in a credit line to the material. If material is not included in the article's Creative Commons licence and your intended use is not permitted by statutory regulation or exceeds the permitted use, you will need to obtain permission directly from the copyright holder. To view a copy of this licence, visit http://creativecommons.org/licenses/by/4.0/ The Creative Commons Public Domain Dedication waiver (http://creativecommons.org/publicdomain/zero/1.0/) applies to the data made available in this article, unless otherwise stated in a credit line to the data. 


\section{Background}

Kenya has witnessed violence in every national election since the introduction of multipartism [1]. The postelection violence that occurred after the disputed general elections in 2007 reported the highest fatalities, loss of property and displacement [2]. Unfortunately majority of the displaced persons are still living in camps for internally displaced persons (IDPs) [2,3].

The displacement and relocation that IDPs go through may lead to weakening or loss of the social support that they had. Social support is the perception or experience that one is loved, cared for, esteemed and valued by others and part of a social network of mutual assistance [4]. This support can come from family, friends, neighbours or organizations in the community. IDPs have also been found to suffer from food insecurity [5] and poor physical health [6]. Little is known regarding the relationship between food security social support, mental health and physical health among IDPs.

The aim of this study was to examine the predictors of social support, physical and mental health among IDPs living in Nakwamekwi IDP Camp, Turkana County.

\section{Methods}

This study used a cross sectional survey. The study was conducted in Nakwamekwi IDP Camp, established in 2008 when people displaced from other volatile regions in the country following the 2007-2008 post-election violence moved backed to Turkana, their original home. Systemic random sampling was used to obtain a sample of household heads from a total of 400 households. To ensure randomization in choosing the first participant (i), participants of the first and second household were made to pick one piece of paper with the number after which the second household was selected. Therefore, the systematic sample consisted of participants in the series; i, $i+l, i+2 l \ldots \ldots \ldots . ., i+(n-1) l$.

Where:

$i=$ the first participant

$l=$ the sampling interval

$n=$ the sample

In this study, a household was defined as a group of people living in the same dwelling compound within the camp while the household head was defined as the person, male or female who was responsible for the general welfare of the other members living in the same household. Only the household head was interviewed as they were better placed to provide an accurate account of the household situation as well as save time and the cost of the survey. A high number of women household heads were sampled in this study supporting findings that women outnumber men in IDP populations [7, 8].

A researcher-administered questionnaire was used to collect data. Mental health was assessed using the
Hopkins Symptom Checklist (HSCL) which consists of 25 items that assess symptoms of anxiety (10 items) depression (15 items). Those with scores of $>1.75$ for each subscale are considered to have depression and anxiety symptoms. This scale has been used among displaced populations $[9,10]$. Physical health was measured using the 7-item short version of the 26 item WHO Quality of Life-BREF (WHOQOL-BREF) tool that has been used in Kenya before [11] and higher scores indicate better physical health while lower scores indicate poor physical health. Social support was measured using the Medical Outcomes Study Social Support Survey (MOS-SSS). This tool contains 19 items which measures tangible support, affectionate support, emotional support and positive social interaction. The MOS-SSS was scored following set guidelines from the authors and higher scores indicate more social support [12]. The Household Food Insecurity Access Scale (HFIAS) was used to measure household food security. The HFIAS consists of nine questions and the scores range from 0 to 27 with lower scores indicating severe food insecurity. Following HFIA $S$ guidelines [13] the households were categorized as food secure or food insecure. Food insecure households were further categorized as having mild food insecurity, moderate food insecurity and severe food insecurity. The HFIAS has been used and validated in several countries [13] and used among various conflict affected population [5].

Data were first entered into Statistical Package for the Social Sciences (SPSS) version 20.0 and thereafter loaded into R [14] for further analysis. The internal consistency of the scales used were: food security $(\alpha=0.86)$, mental health ( $\alpha=0.89$ : anxiety symptoms subscale $\alpha=0.88$, depression symptoms subscale $\alpha=0.84$ ), physical health $(\alpha=0.73)$ and social support $(\alpha=0.92)$. Frequencies, means, and standard deviations were calculated for all the variables. Logistic regression was used to determine predictors of mental health and unadjusted (one variable at a time) and adjusted (all variables in one model) odds ratios were obtained. Multiple linear regression analysis was used to determine predictors of social support and physical health. A value of $p<0.05$ was used to determine statistical significance. Ethical approval was provided by Mount Kenya University Ethical Review Committee (MKU/ERC/0094). Participants provided oral informed consent while confidentiality and anonymity was maintained.

\section{Results}

A total of 159 household heads, also referred to as participants, were interviewed (response rate of 79.1\%). The 159 households comprised of 1059 members $(M=6.66$, $\mathrm{SD} \pm 3.17)$ of which $717(67.70 \%)$ were children aged 18 years and below. The mean age of the participants was 
$47.8(\mathrm{SD} \pm 18.5$, range $18-92)$ and 115 (72.3\%) were female. The participants had lived in the camp for an average of 7.9 ( $\mathrm{SD} \pm 2.2$, range $0.3-11$ ) years, 92 (57.9\%) were married, almost all had primary education and below $(n=152,95.6 \%)$, while 155 (97.5\%) were unemployed. All participants were food insecure with almost all the households experiencing severe food insecurity $(n=149,93.7 \%)$ and none had access to a toilet or protected water source. A summary of participants' characteristics is outlined in Table 1 and histograms of non-categorical variables are shown in Fig. 1 (Online Resource 1).

More than three quarters $(n=123,77.4 \%)$ of the household heads had depression symptoms. In the adjusted analysis (see Table 2), married household heads were less likely to have depression symptoms compared to the unmarried $(\mathrm{AOR}=0.37 ; 95 \% \mathrm{CI}, 0.14-0.92 ; p=$ 0.038). Household heads living in households with five or more children were 3.32 times more likely have depression symptoms compared with those living in households with less than five children ( $\mathrm{AOR}=3.32$; $95 \% \mathrm{CI}$, $1.31-9.24 ; p=0.015)$. Those who had lived in the camp for more than 9 years were 0.24 times more likely have depression symptoms (AOR $=0.24 ; 95 \% \mathrm{CI}, 0.09-0.59$; $p=0.003$ ). Gender, education level, age and number of adults in household were not associated with the risk having depression symptoms (Table 2).

Seventy six percent $(n=121,76.1 \%)$ of the participants had anxiety symptoms. None of the variables were significantly associated with anxiety symptoms in the adjusted analysis (Table 3). However, there was a slight (but not significant) increase in anxiety symptoms with an increase in number children in household as well as the age group of 41-70 years.

Participants tended to have poorer physical health if they had spent more years in the camp $(-1.41 ; 95 \% \mathrm{CI}$, $-2.76--0.04 ; p=0.042)$, were older $(-0.28$; $95 \% \mathrm{CI},-0.44$ $-0.12 ; p=0.001)$, and had more children in their households $(-1.38 ; 95 \% \mathrm{CI}, \quad-2.75-\quad-0.02 ; p=0.047)$, see Table 4 . Social support was significantly associated with marriage and experience of violence in the camp. Those who were married had significantly higher social support $(\mathrm{OR}=8.16,95 \% \mathrm{CI}, 3.22-13.10 ; p=0.001)$, and those who had not experienced violence in the camp had significantly less social support $(\mathrm{R}=-7.69,95 \% \mathrm{CI},-13.09$ -2.28; $p=0.006$ ), see Table 4 .

\section{Discussion}

The health of IDPs is affected by displacement $[15,16]$. The overall prevalence of depression and anxiety symptoms in this study are consistent with findings from other studies conducted among IDPs [6, 10, 11, 16, 17]. These high levels of depression and anxiety symptoms in this study may be attributed to the high prevalence of
Table 1 Demographic characteristics

\begin{tabular}{|c|c|}
\hline $\begin{array}{l}\text { Characteristic } \\
(N=159)\end{array}$ & Mean (SD) / N (\%) \\
\hline$\overline{\text { Age }}$ & $47.8(18.5)$ \\
\hline Household size & $7.1(3.6)$ \\
\hline Children in household & $4.5(2.5)$ \\
\hline Adults in household & $2.6(1.6)$ \\
\hline Years lived in current residence & $7.9(2.2)$ \\
\hline \multicolumn{2}{|l|}{ Gender } \\
\hline Female & $115(72.3 \%)$ \\
\hline Male & $44(27.7 \%)$ \\
\hline \multicolumn{2}{|l|}{ Marital status } \\
\hline Single & $67(42.1 \%)$ \\
\hline Married & $92(57.9 \%)$ \\
\hline \multicolumn{2}{|l|}{ Employment status } \\
\hline Employed & $4(2.5 \%)$ \\
\hline Unemployed & 155 (97.5\%) \\
\hline \multicolumn{2}{|l|}{ Education } \\
\hline Primary education and below & $152(95.6 \%)$ \\
\hline High school education and above & $7(4.4 \%)$ \\
\hline \multicolumn{2}{|c|}{ Experienced violence in current residence (camp) } \\
\hline No Answer & 1 \\
\hline Yes & $42(26.6 \%)$ \\
\hline No & $116(73.4 \%)$ \\
\hline \multicolumn{2}{|c|}{ Lost family members during displacement } \\
\hline No Answer & 1 \\
\hline Yes & $86(54.4 \%)$ \\
\hline No & $72(45.6 \%)$ \\
\hline \multicolumn{2}{|l|}{ Food insecurity } \\
\hline Food Secure & $0(0.0 \%)$ \\
\hline Mild Food Insecurity & $1(0.6 \%)$ \\
\hline Moderate Food Insecurity & $9(5.7 \%)$ \\
\hline Severe Food Insecurity & 149 (93.7\%) \\
\hline \multicolumn{2}{|l|}{ With depression symptoms } \\
\hline Yes & $123(77.4)$ \\
\hline No & $36(22.6)$ \\
\hline \multicolumn{2}{|l|}{ With anxiety symptoms } \\
\hline Yes & $121(76.1)$ \\
\hline No & $38(23.9)$ \\
\hline
\end{tabular}

household food insecurity that may have caused worry and uncertainty among the household heads [18, 19]. Majority of the participants have been in the IDP camp for more than 5 years and long stay in camps has been associated with poor mental health among conflict afflicted populations [6, 15]. However married participants were less likely to have symptoms of 

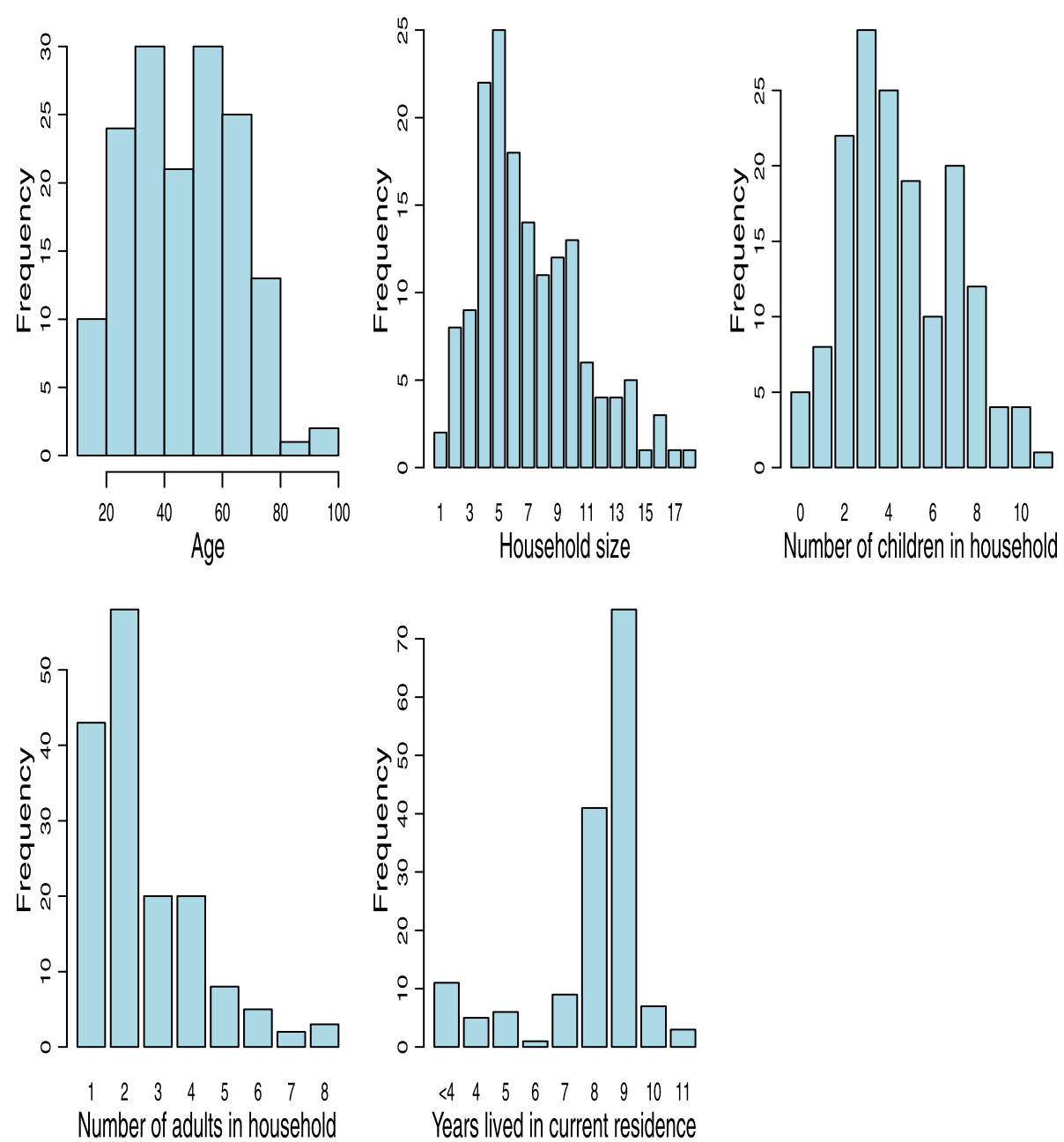

Fig. 1 Histograms of quantitative demographic characteristics

Table 2 Logistic regression analysis for predictors of depression a among IDPs in Turkana Kenya

\begin{tabular}{|c|c|c|c|c|c|c|}
\hline Predictors & AOR & $\mathrm{Cl}$ & $p$-val & UOR & $\mathrm{Cl}$ & $p$-val \\
\hline \multicolumn{7}{|l|}{$(N=159)$} \\
\hline Gender: Male & 0.83 & $0.30-2.30$ & 0.708 & 0.83 & $0.38-1.93$ & 0.661 \\
\hline Marital status: Married & 0.37 & $0.14-0.92$ & 0.038 & 0.45 & $0.19-0.98$ & 0.051 \\
\hline Education: High school education and above & 4.25 & $0.55-92.80$ & 0.230 & 1.79 & $0.29-34.50$ & 0.594 \\
\hline Years lived in current residence: $9-12$ & 0.24 & $0.09-0.59$ & 0.003 & 0.30 & $0.13-0.67$ & 0.005 \\
\hline Age: $41-70$ & 2.36 & $0.90-6.52$ & 0.086 & 2.69 & $1.19-6.33$ & 0.020 \\
\hline Age: $71-100$ & 0.97 & $0.26-3.96$ & 0.962 & 1.00 & $0.32-3.52$ & 1.000 \\
\hline Adults in household: 6-15 & 0.40 & $0.07-3.27$ & 0.335 & 1.18 & $0.28-8.08$ & 0.837 \\
\hline Children in household: $5-11$ & 3.32 & $1.31-9.24$ & 0.015 & 2.48 & $1.13-5.79$ & 0.028 \\
\hline Experienced violence in current residence (camp): No & 1.04 & $0.39-2.65$ & 0.929 & 1.08 & $0.45-2.44$ & 0.853 \\
\hline Lost family members during displacement: No & 0.99 & $0.40-2.48$ & 0.976 & 0.92 & $0.43-1.95$ & 0.821 \\
\hline
\end{tabular}

${ }^{\mathrm{a}}$ Hopkins Symptom Checklist (HSCL); cut off points $>1.75$ symptoms of depression 
Table 3 Logistic regression analysis for predictors of anxiety ${ }^{a}$ among IDPs in Turkana Kenya

\begin{tabular}{|c|c|c|c|c|c|c|}
\hline Predictors & AOR & $\mathrm{Cl}$ & $p$-val & UOR & $\mathrm{Cl}$ & $p$-val \\
\hline \multicolumn{7}{|l|}{$(N=159)$} \\
\hline Gender: Male & 0.47 & $0.18-1.19$ & 0.109 & 0.66 & $0.30-1.48$ & 0.304 \\
\hline Marital status: Married & 0.63 & $0.27-1.46$ & 0.290 & 0.55 & $0.25-1.18$ & 0.134 \\
\hline Education: High school education and above & 1.36 & $0.25-10.69$ & 0.740 & 0.78 & $0.16-5.58$ & 0.767 \\
\hline Years lived in current residence: $9-12$ & 0.58 & $0.25-1.31$ & 0.198 & 0.60 & $0.28-1.26$ & 0.186 \\
\hline Age: $41-70$ & 2.09 & $0.84-5.41$ & 0.118 & 2.01 & $0.92-4.48$ & 0.081 \\
\hline Age: $71-100$ & 1.80 & $0.47-8.23$ & 0.410 & 1.36 & $0.42-5.35$ & 0.626 \\
\hline Children in household: $\mathbf{5 - 1 1}$ & 2.10 & $0.92-4.99$ & 0.084 & 1.99 & $0.94-4.44$ & 0.079 \\
\hline Experienced violence in current residence (camp): No & 1.66 & $0.69-3.92$ & 0.249 & 1.72 & $0.76-3.77$ & 0.181 \\
\hline Lost family members during displacement: No & 1.37 & $0.58-3.34$ & 0.482 & 1.13 & $0.54-2.40$ & 0.745 \\
\hline
\end{tabular}

${ }^{a}$ Hopkins Symptoms Checklist (HSCL); cut off points > 1.75 symptoms of anxiety

depression supporting evidence marriage promotes mental health $[6,20,21]$.

Older participants had poor health and these results are supported by other studies on IDPs [22]. Longer duration in the IDP camp was also associated with poor health [11, 17]. Participants in households with many adults and children were more likely to have poor health. IDP camps are usually overcrowded [23, 24] and this particular camp in Turkana is no exception and crowded conditions negatively affects health by facilitating spread of communicable diseases [23, 24]. High unemployment rates may also have contributed to the poor physical health. High food insecurity levels, lack of toilets and protected water sources may have contributed to participants' poor health, as poor sanitation and food insecurity is a major contributor of poor health among conflict afflicted populations $[6,24]$.
Marriage is seen as offering social support, an important component of social health hence the high levels of social support among the married participants [20, 25]. Participants who had lost family members during displacement experienced violence in the camp, findings that show family members are a source of social support and people with low social support are more vulnerable to victimization and violence $[26,27]$.

Some limitations should be considered when interpreting this study's results. First, due to lack of funds only one camp was visited and the sample size was also limited. Thus the results may vary with those from other IDP camps in the country as well as explain why few predictors were statistically significant. Second the measures used to measure depression and anxiety are for screening possible symptoms and not diagnostic. Third, poor specificity of the mental health measure may have

Table 4 Multiple linear regression analysis for predictors of physical and social health among IDPs in Turkana Kenya

\begin{tabular}{|c|c|c|c|c|c|c|}
\hline \multirow[b]{2}{*}{ Predictors } & \multicolumn{3}{|c|}{ Physical health* } & \multicolumn{3}{|c|}{ Social health** } \\
\hline & Estimates & $\mathrm{Cl}$ & $p$ & Estimates & $\mathrm{Cl}$ & $p$ \\
\hline \multicolumn{7}{|l|}{$(N=159)$} \\
\hline Gender: Male & -0.25 & $-6.72-6.22$ & 0.940 & 1.29 & $-4.17-6.76$ & 0.641 \\
\hline Marital status: Married & 0.50 & $-5.35-6.34$ & 0.867 & $8.16^{* *}$ & $3.22-13.10$ & 0.001 \\
\hline Education: High schooleducation and above & 5.50 & $-8.04-19.05$ & 0.423 & 2.30 & $-9.14-13.74$ & 0.692 \\
\hline Years lived in currentresidence & $-1.41^{*}$ & $-2.76--0.05$ & 0.042 & -0.10 & $-1.25-1.04$ & 0.863 \\
\hline Age & $-0.28^{* * *}$ & $-0.44--0.12$ & 0.001 & -0.04 & $-0.18-0.09$ & 0.540 \\
\hline Adults in household & -0.37 & $-2.49-1.76$ & 0.732 & -0.17 & $-1.96-1.63$ & 0.855 \\
\hline Children in household & $-1.38^{*}$ & $-2.75--0.02$ & 0.047 & 0.21 & $-0.95-1.36$ & 0.722 \\
\hline Experienced violence incurrent residence (camp): No & 3.12 & $-3.28-9.52$ & 0.336 & $-7.69^{* *}$ & $-13.09--2.28$ & 0.006 \\
\hline Lost family membersduring displacement: No & 0.10 & $-5.81-6.01$ & 0.974 & 4.90 & $-0.09-9.89$ & 0.054 \\
\hline Observations & \multicolumn{3}{|l|}{155} & \multicolumn{3}{|l|}{155} \\
\hline$R^{2} / R^{2}$ adjusted & \multicolumn{3}{|l|}{$0.200 / 0.151$} & \multicolumn{3}{|l|}{$0.181 / 0.130$} \\
\hline
\end{tabular}

${ }^{*} p<0.05 * * p<0.01 * * * p<0.001$

*WHOQOL-BREF (WHO Quality of Life-BREF); higher scores indicate better physical health

${ }^{*}$ Medical Outcomes Study Social Support Survey; higher scores indicate more social support 
resulted to a high percentage of participants indicating depression and anxiety symptoms.

\section{Conclusion}

The National and County governments should consider resettling the IDPs who have overstayed in the camp in order to improve their physical, mental and social wellbeing. Meanwhile, provision of food, safe drinking water and toilets should be done to mitigate food insecurity and improve the health of the IDPs in the camp.

\section{Abbreviations}

IDP: Internally Displaced Persons; AOR: Adjusted odds ratio; UOR: Unadjusted odds ratio

\section{Acknowledgements}

We are grateful to all the study participants for taking time to participate in this study.

\section{Authors' contributions}

CG conceived the study, collected and prepared the data and wrote the first draft. DM made substantial contributions to the acquisition and collection of the data. JB made substantial contributions to the analysis and interpretation of the data. All authors critically revised and approved the final manuscript.

\section{Funding}

Not applicable.

\section{Availability of data and materials}

The datasets used and/or analyzed during the current study are available from the corresponding author on reasonable request.

\section{Ethics approval and consent to participate}

To be inserted after review.

\section{Consent for publication}

Not applicable.

\section{Competing interests}

The authors declare they have no competing interests.

\section{Author details}

${ }^{1}$ School of Nursing and Public Health, Chuka University, Chuka, Kenya ${ }^{2}$ School of Science and Technology, Turkana University College, Turkana, Kenya. ${ }^{3}$ Department of Mathematics, Applied Mathematics, and Statistics, Case Western Reserve University, Cleveland, USA. ${ }^{4}$ Faculty of Physical Sciences, University of Iceland, Reykjavik, Iceland.

Received: 1 April 2020 Accepted: 28 July 2020

Published online: 07 August 2020

\section{References}

1. Mbugua JK. Casting the bad omen: preventing electoral violence in Kenya. AfricA AMANI. 2017;20:20-40

2. iDMC. Kenya: IDPS' significant needs remain as inter-communical violence increases 2012. Available from: https://www.internal-displacement.org/sites/ default/files/publications/documents/201212-af-kenya-overview-en.pdf. Cited 2012 May 22nd 2020.

3. iDMC. The ripple effect: Economic impacts of internal displacement: iDMC; 2020. Available from: https://www.internal-displacement.org/sites/default/ files/publications/documents/202001-cost-of-displacement-africa-casestudies.pdf. Cited 2020 May 22nd 2020.

4. Wills TA. Social support and interpersonal relationships; 1991.

5. Singh KP, Bhoopathy SV, Worth $H$, Seale H, Richmond RL. Nutrition among men and household food security in an internally displaced persons camp in Kenya. Public Health Nutr. 2015;19(4):723-31.

6. Roberts B, Damundu EY, Lomoro O, Sondorp E. The influence of demographic characteristics, living conditions, and trauma exposure on the overall health of a conflict-affected population in southern Sudan. BMC Public Health. 2010;10(1):518.

7. Cohen R, Deng F. Masses in flight: the global crisis of internal displacement; 1998.

8. Buvinic M, Gupta MD, Casabonne U, Verwimp P. Violent conflict and gender inequality: an overview: the World Bank; 2013.

9. Mollica R, Wyshak G, de Marnette D, Tu B, Yang T, Khuon F, et al. Hopkins symptoms checklist 25 (HSCL-25): manual Cambodian, Laotian and Vietnamese versions. Torture. 1996;6(Suppl. 1):35-42.

10. Sheikh TL, Abdulaziz M, Agunbiade S, Joseph I, Ebiti B, Adekeye O. Correlates of depression among internally displaced persons after postelection violence in Kaduna, North Western Nigeria. J Affect Disorders. 2015; 170:46-51.

11. Getanda EM, Papadopoulos C, Evans H. The mental health, quality of life and life satisfaction of internally displaced persons living in Nakuru County. Kenya BMC Public Health. 2015;15(1):755.

12. Sherbourne CD, Stewart AL. The MOS social support survey. Soc Sci Med. 1991;32(6):705-14

13. Coates J, Swindale A, Bilinsky P. Household food insecurity access scale (HFIAS) for measurement of household food access: indicator guide (v. 3). 2007. Washington, DC: Food and Nutrition echnical Assistance Project, Academy for Educational Development; 2016.

14. Team RC. R: a language and environment for statistical computing: a graduate course in probability. Vienna: R Foundation for Statistical Computing; 2018.

15. Siriwardhana C, Adikari A, Pannala G, Siribaddana S, Abas M, Sumathipala A, et al. Prolonged internal displacement and common mental disorders in Sri Lanka: the COMRAID study. PloS one. 2013;8(5):e64742.

16. Kim G, Torbay R, Lawry L. Basic health, women's health, and mental health among internally displaced persons in Nyala Province, South Darfur, Sudan. Ame J Public Health. 2007:97(2):353-61.

17. Owoaje ET, Uchendu OC, Ajayi TO, Cadmus EO. A review of the health problems of the internally displaced persons in Africa. Nigerian Postgraduate Med J. 2016;23(4):161

18. Hadley C, Tegegn A, Tessema F, Cowan JA, Asefa M, Galea S. Food insecurity, stressful life events and symptoms of anxiety and depression in East Africa: evidence from the Gilgel gibe growth and development study. J Epidemiol Commun H. 2008;62(11):980-6.

19. Jones AD. Food insecurity and mental health status: a global analysis of 149 countries. Am J Pre Med. 2017;53(2):264-73.

20. Kessler RC, Essex M. Marital status and depression: the importance of coping resources. Soc Forces. 1982:61(2):484-507.

21. Koball HL, Moiduddin E, Henderson J, Goesling B, Besculides M. What do we know about the link between marriage and health? J Fam Issues. 2010;31(8): 1019-40.

22. Karunakara U, Stevenson F. Ending neglect of older people in the response to humanitarian emergencies. PLoS Med. 2012;9(12):e1001357.

23. Gbakima A, Terry B, Kanja F, Kortequee S, Dukuley I, Sahr F. High prevalence of bedbugs Cimex hemipterus and Cimex lectularis in camps for internally displaced persons in Freetown, Sierra Leone: a pilot humanitarian investigation. West Afr J Med. 2002;21(4):268-71.

24. Lam E, McCarthy A, Brennan M. Vaccine-preventable diseases in humanitarian emergencies among refugee and internally-displaced populations. Hum Vacc Immunother. 2015;11(11):2627-36.

25. Dehle C, Larsen D, Landers JE. Social support in marriage. Am J Fam Ther. 2001;29(4):307-24

26. Ribeiro MRC, da Silva AAM, de Britto MTSS. Effects of socioeconomic status and social support on violence against pregnant women: a structural equation modeling analysis. PLoS one. 2017;12(1):e0170649.

27. Sigalla GN, Rasch V, Gammeltoft T, Meyrowitsch DW, Rogathi J, Manongi R, et al. Social support and intimate partner violence during pregnancy among women attending antenatal care in Moshi municipality, Northern Tanzania. BMC Public Health. 2017;17(1):240

\section{Publisher's Note}

Springer Nature remains neutral with regard to jurisdictional claims in published maps and institutional affiliations. 